\title{
Creation of a microstructured polymer optical fiber with UV Bragg grating inscription for the detection of extensions at temperatures up to $125^{\circ} \mathrm{C}$
}

\author{
Fasano, Andrea; Woyessa, Getinet; Stajanca, Pavol; Markos, Christos; Stefani, Alessio ; Nielsen, \\ Kristian; Rasmussen, Henrik K.; Krebber, Katerina; Bang, Ole
}

\section{Published in:}

Proceedings of SPIE 9886

Link to article, DOI:

$10.1117 / 12.2227843$

Publication date:

2016

Document Version

Publisher's PDF, also known as Version of record

Link back to DTU Orbit

\section{Citation (APA):}

Fasano, A., Woyessa, G., Stajanca, P., Markos, C., Stefani, A., Nielsen, K., Rasmussen, H. K., Krebber, K., \& Bang, O. (2016). Creation of a microstructured polymer optical fiber with UV Bragg grating inscription for the detection of extensions at temperatures up to $125^{\circ} \mathrm{C}$. In K. Kalli, \& A. Mendez (Eds.), Proceedings of SPIE 9886 : Micro-Structured and Specialty Optical Fibres IV (Vol. 9886). [988619] SPIE - International Society for Optical Engineering. Proceedings of SPIE - The International Society for Optical Engineering https://doi.org/10.1117/12.2227843

\section{General rights}

Copyright and moral rights for the publications made accessible in the public portal are retained by the authors and/or other copyright owners and it is a condition of accessing publications that users recognise and abide by the legal requirements associated with these rights.

- Users may download and print one copy of any publication from the public portal for the purpose of private study or research.

- You may not further distribute the material or use it for any profit-making activity or commercial gain

- You may freely distribute the URL identifying the publication in the public portal 


\title{
Creation of a microstructured polymer optical fiber with UV Bragg grating inscription for the detection of extensions at temperatures up to $125^{\circ} \mathrm{C}$
}

\author{
Andrea Fasano ${ }^{\mathrm{a}}$, Getinet Woyessa ${ }^{\mathrm{b}}$, Pavol Stajanca ${ }^{\mathrm{c}}$, Christos Markos ${ }^{\mathrm{b}, \mathrm{d}}$, Alessio Stefani ${ }^{\mathrm{b}, \mathrm{e}}$, Kristian \\ Nielsen $^{\mathrm{b}}$, Henrik K. Rasmussen ${ }^{\mathrm{a}}$, Katerina Krebber ${ }^{\mathrm{c}}$, Ole Bang ${ }^{\mathrm{b}}$ \\ ${ }^{a}$ DTU Mekanik, Department of Mechanical Engineering, Technical University of Denmark, 2800 \\ Kgs. Lyngby, Denmark; ${ }^{b}$ DTU Fotonik, Department of Photonics Engineering, Technical University \\ of Denmark, 2800 Kgs. Lyngby, Denmark; 'Division 8.6 "Optical and Fibre Optic Methods", BAM \\ Federal Institute for Materials Research and Testing, 12205 Berlin, Germany; ${ }^{\mathrm{d} C R E O L}$, The College \\ of Optics \& Photonics, University of Central Florida, 4000 Central Florida Blvd., Orlando, FL \\ 32816, USA; ${ }^{\mathrm{e} I n s t i t u t e}$ of Photonics and Optical Science (IPOS), School of Physics, The University \\ of Sydney, NSW 2006, Australia
}

\begin{abstract}
We describe the fabrication of a polycarbonate (PC) micro-structured polymer optical fiber (mPOF) and the writing of fiber Bragg gratings (FBGs) in it to enable strain and temperature measurements. We demonstrate the photosensitivity of a dopant-free PC fiber by grating inscription using a UV laser. We further show that PC Bragg gratings can be extended up to at least 3\% without affecting the initial functionality of the micro-structured fiber. The response of PC FBGs to temperature up to $125^{\circ} \mathrm{C}$ is also investigated. Polycarbonate has good mechanical properties and its high temperatureresistance might extend the range of application of polymeric FBGs.
\end{abstract}

Keywords: Polycarbonate, polymers, micro-structured polymer optical fibers, UV laser inscription, optical fiber sensors, fiber Bragg gratings

\section{INTRODUCTION}

The use of polymers instead of silica in optical fiber Bragg grating (FBG) sensors offers several advantages. Polymer optical fibers (POFs) have a higher elastic strain limit and a lower stiffness than glass fibers. ${ }^{1}$ Further important properties such as biocompatibility, low densities, flexibility, and non-brittle nature altogether represent key advantages over silica. Because of their unique characteristics, polymeric FBGs are particularly attractive for a broad range of technological applications, including temperature and strain sensing devices. Micro-structured polymer optical fibers (mPOFs) offer a wide range of optical effects obtainable by varying their internal microstructure. The possibility of guiding light in this class of fibers is based on a patterning of air holes extending along the fiber. ${ }^{2-3}$ Here we report on the fabrication of a polycarbonate (PC) $\mathrm{mPOF}$ and the inscription of PC FBGs for strain and temperature sensing. We show that these devices can be used up to $125^{\circ} \mathrm{C}$. In 2006 photosensitivity studies on PC carried out by Migahed and Zidan showed that the refractive index profile of PC films was affected by UV irradiation. This suggests a potential applicability of the photo-irradiation in PC-based optical devices such as PC FBGs. In this paper we demonstrate the photosensitivity of a dopant-free PC mPOF by UV laser writing. Polycarbonate mPOFBGs were extended up to $3 \%$ of the original dimension maintaining their initial functionality. A linear response to temperature up to $125^{\circ} \mathrm{C}$ was also observed. Note that it is possible for a polymeric FBG to withstand temperatures as high as $125^{\circ} \mathrm{C}$ only if a high glass transition temperature $\left(\mathrm{T}_{\mathrm{g}}\right)$ plastic material such as PC is used. In the last fifteen years most research on the polymeric FBGs has focused on PMMA, based on the first investigations done at the end of 1990s. ${ }^{5-6}$ Other possible plastic materials are TOPAS and CYTOP. The temperature stabilities of PMMA and TOPAS FBGs have been demonstrated up to $92^{\circ} \mathrm{C}^{7}$ and $110^{\circ} \mathrm{C},{ }^{8}$ respectively.

*andfas@mek.dtu.dk; phone +45 45254776; http://www.mek.dtu.dk

Micro-Structured and Specialty Optical Fibres IV, edited by Kyriacos Kalli,

Alexis Mendez, Proc. of SPIE Vol. 9886, 988619 - (C) 2016 SPIE

CCC code: $0277-786 X / 16 / \$ 18 \cdot$ doi: $10.1117 / 12.2227843$

Proc. of SPIE Vol. $9886988619-1$ 
Polycarbonate-based micro-structured fibers have drawn some attention over the last decade, ${ }^{9-13}$ whereas PC optical fibers have been studied and used since the $1980 \mathrm{~s} .{ }^{14-17} \mathrm{PC}$ as the core material in a POF was developed for the first time by Fujitsu in $1986 .{ }^{18}$ Besides its thermal resistance being among the highest in the class of transparent polymers, this material also has an excellent transparency to visible light. Overall, it represents a natural alternative to PMMA, which is the material most commonly used for the manufacture of POFs. However, the use of PMMA FBGs is limited to moderate temperatures. This constraint is less severe for PC because of its elevated $\mathrm{T}_{\mathrm{g}}$. Other attractive characteristics of the latter are elevated impact resistance and high failure strain. Polycarbonate further exhibits good flexibility in bending. Figure 1 shows a PC micro-structured cane with an average diameter of approximately $3.5 \mathrm{~mm}$ being initially bent (a) and then completely twisted (b).

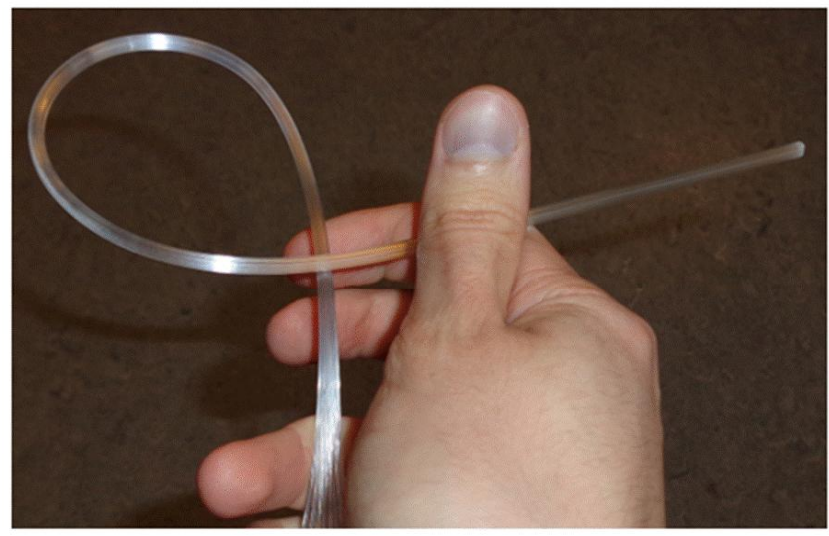

(a)

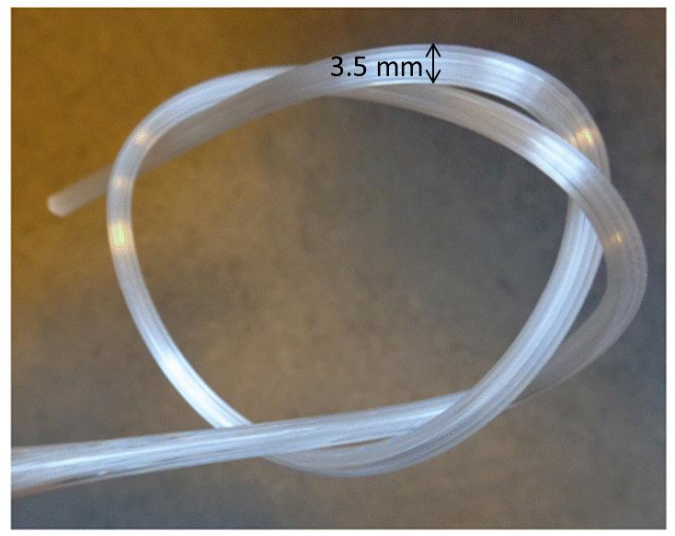

(b)

Figure 1. (a) An in-house made PC cane is initially bent, and then (b) knotted. The average diameter of the cane is around $3.5 \mathrm{~mm}$. In addition to its high impact resistance, $\mathrm{PC}$ has good flexibility in bending even at room temperature.

\section{POLYCARBONATE MPOFBG MANUFACTURING}

\subsection{PC mPOF fabrication}

The manufacturing of PC fibers consisted of multiple fabrication stages, involving the molding of an optical-grade PC (Makrolon LED2245) with a $\mathrm{T}_{\mathrm{g}}$ of $145^{\circ} \mathrm{C}$, the drilling of the desired hole arrangement, and the drawing of the polymer preform using a draw tower. We observed that the particular choice of both processing temperature and pressure had a significant impact on the quality of the final fiber. In our experiments high-temperature casting was required to obtain optical fibers as homogeneous as possible. After molding the solid rods were machined to preforms with a diameter of 60 $\mathrm{mm}$ and a length of $100 \mathrm{~mm}$. A patterning of 36 holes with a diameter of $3 \mathrm{~mm}$ hexagonally arranged around the solid core was drilled by using a computer numerical control (CNC) drilling machine. The fibers were manufactured in two different drawing stages. First we drew down the preforms to intermediate canes. Then we sleeved the canes using inhouse made PC tubes and drew them to final fibers. A more detailed description of the drill-and-draw method can be found in Large et al. ${ }^{3}$ The geometrical characteristics of a solid-core PC mPOF are reported in Table 1. This fiber was endlessly single-mode as the ratio of the hole diameter to the hole pitch is $40 \%$. Further details can be found in Fasano et al. ${ }^{19}$

Table 1. Geometrical parameters of an endlessly single-mode PC mPOF (3-ring hole arrangement).

\begin{tabular}{|l|l|}
\hline Fiber diameter & $150 \mu \mathrm{m}$ \\
\hline Core diameter & $7 \mu \mathrm{m}$ \\
\hline Air hole diameter & $1.75 \mu \mathrm{m}$ \\
\hline Air hole pitch & $4.375 \mu \mathrm{m}$ \\
\hline Hole diameter/hole pitch & $40 \%$ \\
\hline
\end{tabular}




\subsection{FBG writing}

We inscribed Bragg gratings into the endlessly single-mode PC mPOF using the phase mask technique with a $50 \mathrm{~mW}$ CW HeCd laser (325 nm, IK5751I-G, Kimmon). We used a customized phase mask (Ibsen Photonics A/S) with a uniform period of $572.4 \mathrm{~nm}$. Several FBGs were inscribed in the mPOF. Figure 2 shows an example of the resulting reflection spectrum (room temperature) for a PC mPOFBG. The resonance wavelength and the strength of the reflected peak were $892.2 \mathrm{~nm}$ and $15 \mathrm{~dB}$, respectively.

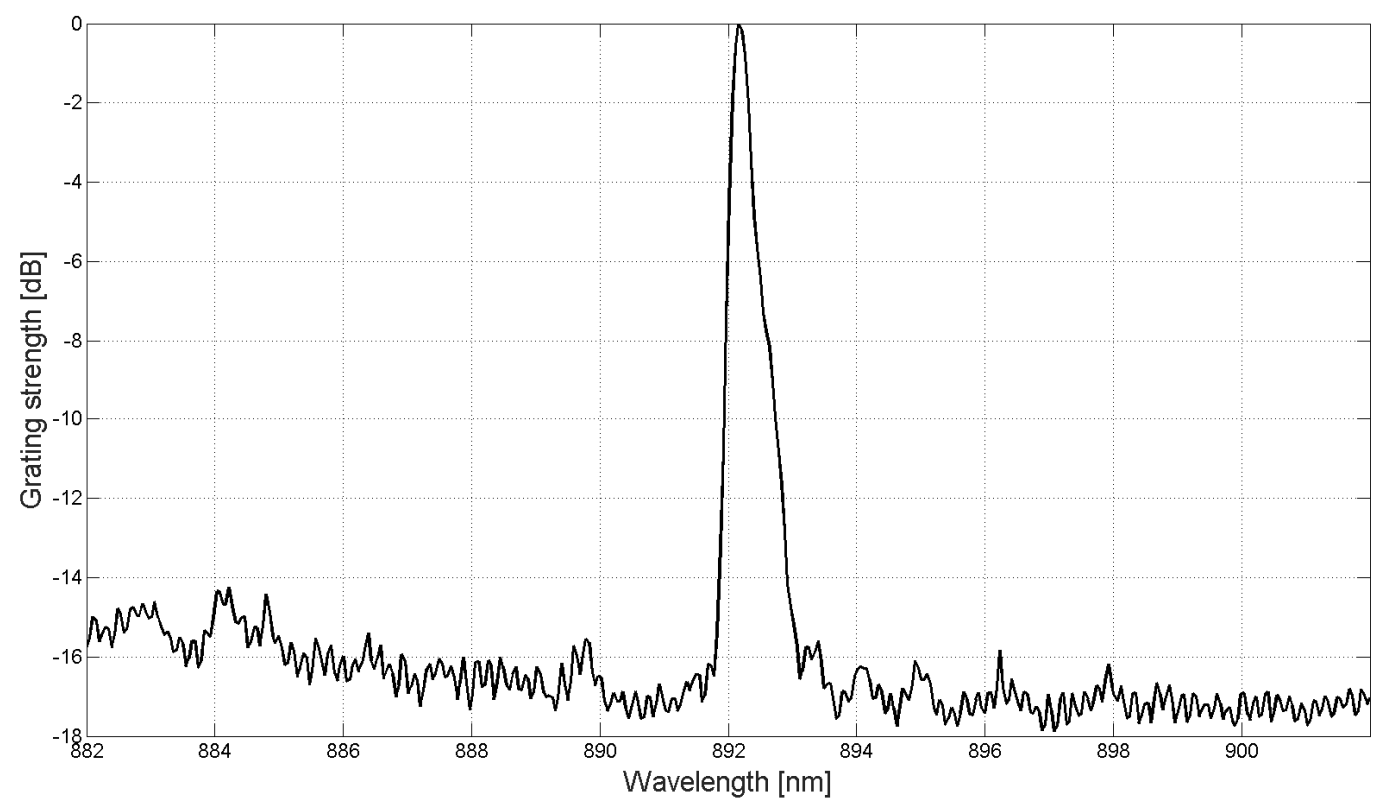

Figure 2. PC mPOFBG spectrum at room temperature. Bragg wavelength: $892.2 \mathrm{~nm}$. Grating strength: $15 \mathrm{~dB}$.

We observed that, on average, 6 minutes was sufficient to write Bragg gratings at a laser power as low as $4 \mathrm{~mW}$. This process was fast, also considering that the holes surrounding the micro-structured fiber core tend to scatter a considerable amount of power throughout the grating inscription. This suggests that PC has a good photosensitivity. Note that, by using a $\mathrm{HeCd}$ laser, the fastest writing process demonstrated for a dopant-free PMMA mPOFBG ${ }^{20}$ was around 7 minutes using a greater power $(30 \mathrm{~mW})$. We further applied post-inscription annealing in order to enhance the grating stability at high temperatures. This had the effect of blue shifting the Bragg resonance wavelength.

\section{POLYCARBONATE MPOFBG CHARACTERIZATION}

\subsection{FBG response to strain}

We tested the PC mPOFBG response to mechanical stretching using a fiber coupler, a supercontinuum source (SuperK Compact, NKT Photonics A/S), and an optical spectrum analyzer (OSA, Ando AQ6315A). We glued both ends of a fiber onto two translation stages. One translation stage was free to move so as to apply the required strain, whereas the other one was kept in a fixed position. We butt coupled the fiber end that was not moving to a silica step-index fiber and launched light through it. The percentage strain in the axial direction was calculated as $\varepsilon=100 \cdot\left(\mathrm{L} / \mathrm{L}_{0}-1\right)$. Here $\mathrm{L}_{0}$ represents the initial length at time $\mathrm{t}_{0}$ and $\mathrm{L}$ denotes the length of the sample under stretching at time $\mathrm{t}$. We read the spectra 10 minutes after varying the axial strain value. We did so in order to avoid misreading of the Bragg resonance wavelength due to the viscoelastic response of the polymer fiber. Figure 3(a) shows the peak wavelength shift recorded during fiber straining. 
(a)

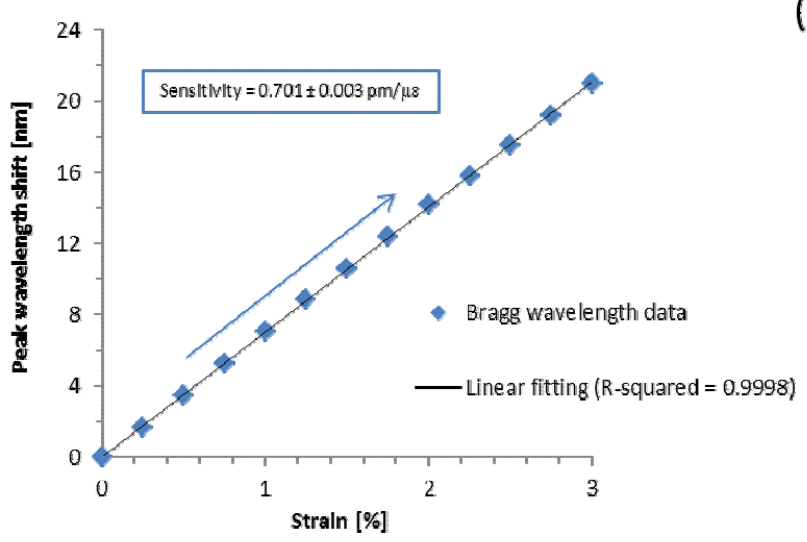

(b)

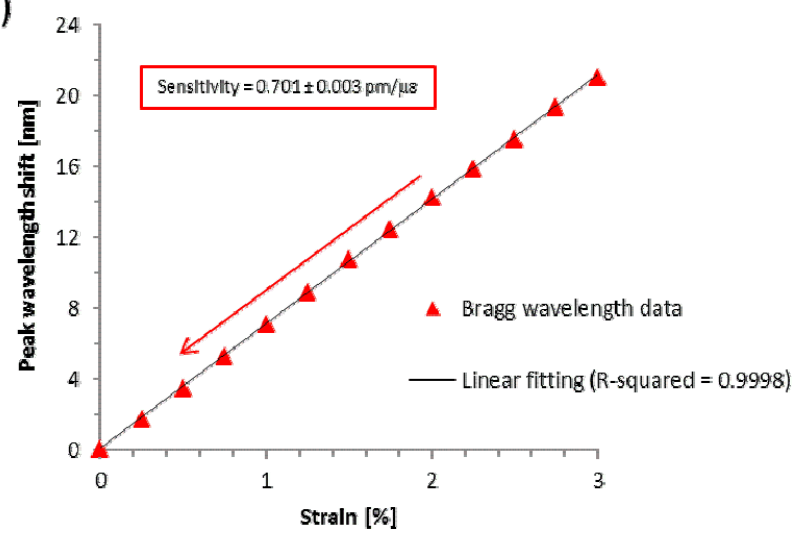

Figure 3. Peak wavelength shift versus strain in the (a) loading and unloading (b) tests at room temperature.

The response was linear over the range $0.0-3.0 \%$. The peak wavelength increased with increasing strain. The total redshift at $\varepsilon=3 \%$ was $21 \mathrm{~nm}$. Using linear regression we calculated a sensitivity of $0.701 \pm 0.003 \mathrm{pm} / \mu \varepsilon$. Table 2 summarizes the comparison between our fiber and other mPOFBGs made of PMMA and TOPAS from the literature. The value of $0.70 \mathrm{pm} / \mu \varepsilon$ obtained for PC is very close to $0.71 \mathrm{pm} / \mu \varepsilon$ reported for PMMA at similar wavelengths. ${ }^{21-22}$ Also note that the sensitivity of low- $\mathrm{T}_{\mathrm{g}}$ TOPAS (8007S-04) reported by Huan et al. ${ }^{23}(0.64 \mathrm{pm} / \mu \varepsilon)$ is lower than that of PC. Figure $3(\mathrm{~b})$ further shows the data obtained from the reverse straining test. The response was again linear between $3.0 \%$ and $0.0 \%$. Also in this case the sensitivity to strain was $0.701 \pm 0.003 \mathrm{pm} / \mu \varepsilon$. This indicates that overall the straining process involved no hysteresis.

Table 2. Sensitivities to strain for mPOFBGs made of different materials.

\begin{tabular}{|l|l|l|l|}
\hline \multicolumn{1}{|c|}{ Material } & \multicolumn{1}{|c|}{$\begin{array}{c}\text { Bragg resonance } \\
\text { wavelength } \\
\text { (unstrained FBG) } \\
{[\mathbf{n m}]}\end{array}$} & $\begin{array}{c}\text { Sensitivity } \\
{[\mathbf{p m} / \boldsymbol{\mu} \varepsilon]}\end{array}$ & \multicolumn{1}{c|}{$\begin{array}{c}\text { Test strain range } \\
{[\%]}\end{array}$} \\
\hline PC & 876 & 0.70 & $0.0-3.0$ \\
\hline PMMA $^{21}$ & 827 & 0.71 & $0.0-1.0$ \\
\hline PMMA $^{22}$ & 848 & 0.71 & $0.0-2.0$ \\
\hline TOPAS $^{23}$ & 869 & 0.64 & $0.0-2.2$ \\
\hline
\end{tabular}

\subsection{FBG response to temperature}

We further tested the PC mPOFBG response to temperature over the range $23.6-125.0^{\circ} \mathrm{C}$ using the same optical setup as the straining test. We put a fiber onto a resistive hot stage for temperature control and covered it with many layers of lens paper to ensure a uniform heat distribution. We used a thermocouple (uncertainty: $0.3^{\circ} \mathrm{C}$ ) to monitor the fiber temperature throughout the test. Each time we set a new temperature, we waited for 15 minutes before reading the FBG reflection spectrum. Figure 4(a) displays the linear behavior exhibited by the FBG when the temperature was ramped up. The peak wavelength decreased with increasing temperature. The total shift measured at $125^{\circ} \mathrm{C}$ was $-3.1 \mathrm{~nm}$. By linear regression of the resonance wavelength data over temperature we calculated the sensitivity to be equal to $-29.99 \pm 0.17$ $\mathrm{pm} /{ }^{\circ} \mathrm{C}$. However, the potential cross-sensitivity of PC mPOFBGs to humidity might have affected the grating response. Since PC is hygroscopic, its intrinsic sensitivity to water should also be taken into account in order to assess the true value of the sensitivity to temperature. A further complication arises from the fact that the dependence on temperature 
and humidity is not independent. ${ }^{1,24}$ Future investigations will evaluate the true PC FBG responses to temperature and humidity in an environmental chamber.

(a)

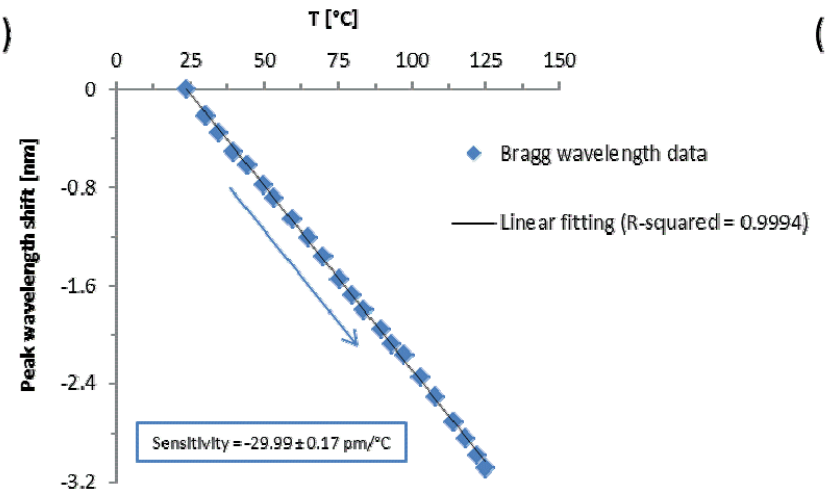

(b)

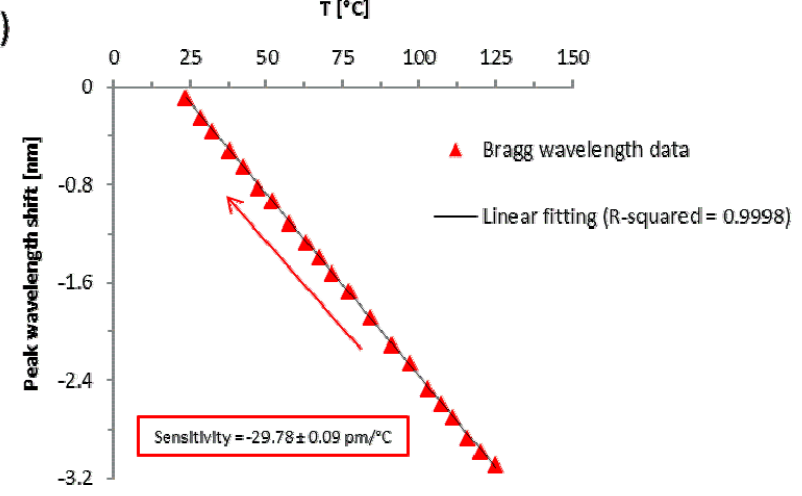

Figure 4. Peak wavelength shift versus temperature in the (a) heating and (b) cooling tests for an unstrained fiber.

Figure 4(b) displays the behavior of the grating when we ramped down the temperature. The response was still linear between $125^{\circ} \mathrm{C}$ and room temperature. The $\mathrm{FBG}$ did not show any significant hysteresis and its sensitivity was almost unaffected $\left(-29.78 \pm 0.09 \mathrm{pm} /{ }^{\circ} \mathrm{C}\right)$. This demonstrates that annealed PC mPOFBGs can work within this operational temperature range. This property suggests their applicability in the automotive industry, e.g., in the engine compartment of a vehicle, where temperatures can reach $125^{\circ} \mathrm{C} .{ }^{14}$ Another advantage of $\mathrm{PC}$ is that it can be steam autocleaved $\left(121^{\circ} \mathrm{C}\right.$, 15-20 minutes). This could open up potential applications of PC FBGs as biomedical sensing devices.

\section{CONCLUSION}

In this work we have described the manufacturing of an endlessly single-mode mPOF made of PC for UV writing of FBGs that can sense strain and temperature. We have shown that strains up to at least $3 \%$ can be detected by using PC Bragg gratings. A stable response to temperature up to $125^{\circ} \mathrm{C}$, linear for an unstrained fiber, has also been demonstrated.

\section{ACKNOWLEDGMENTS}

The research leading to these results has received funding from the People Programme (Marie Curie Actions) of the European Union's Seventh Framework Programme FP7/2007-2013/ under REA grant agreement $\mathrm{n}^{\circ}$ 608382. The authors also acknowledge Financial support from Innovation Fund Denmark for the project ShapeOCT (J. No. 4107-00011A). C.M. acknowledges support from Danish Council for Independent Research (FTP Case No. 4184-00359B). A.S. acknowledges the Eugen Lommel Stipend for financial support.

\section{REFERENCES}

[1] Webb, D. J., "Polymer Fiber Bragg Grating Sensors and Their Applications," in [Optical Fiber Sensors: Advanced Techniques and Applications], G. Rajan ed., CRC Press, 257-276 (2015).

[2] van Eijkelenborg, M. A., Large, M. C. J., Argyros, A., Zagari, J., Manos, S., Issa, N. A., Bassett, I., Fleming, S., McPhedran, R. C., de Sterke, C. M. and Nicorovici, N. A. P., "Microstructured polymer optical fibre," Opt. Express 9(7), 319-327 (2001).

[3] Large, M. C. J., Poladian, L., Barton, G. W. and van Eijkelenborg, M. A., [Microstructured Polymer Optical Fibres], Springer, (2008). 
[4] Migahed, M. D. and Zidan, H. M., "Influence of UV-irradiation on the structure and optical properties of polycarbonate films," Curr. Appl. Phys. 6(1), 91-96 (2006).

[5] Peng, G. D., Xiong, Z. and Chu, P. L., "Photosensitivity and gratings in dye-doped polymer optical fibers," Opt. Fiber Technol. 5(2), 242-251 (1999).

[6] Xiong, Z., Peng, G. D., Wu, B. and Chu, P. L., "Highly tunable Bragg gratings in single-mode polymer optical fibers," IEEE Photon. Technol. Lett. 11(3), 352-354 (1999).

[7] Carroll, K. E., Zhang, C., Webb, D. J., Kalli, K., Argyros, A. and Large, M. C. J., "Thermal response of Bragg gratings in PMMA microstructured optical fibers," Opt. Express 15(14), 8844-8850 (2007).

[8] Markos, C., Stefani, A., Nielsen, K., Rasmussen, H. K., Yuan, W. and Bang, O., "High-Tg TOPAS microstructured polymer optical fiber for fiber Bragg grating strain sensing at 110 degrees," Opt. Express 21(4), 4758-4765 (2013).

[9] van Eijkelenborg, M. A., Argyros, A. and Leon-Saval, S. G., "Polycarbonate hollow-core microstructured optical fiber," Opt. Lett. 33(21), 2446-2448 (2008).

[10] Woliński, T. R., Tefelska, M., Mileńko, K., Siarkowska, A., Budaszewski, D., Domański, A. W., Ertman, S., Orzechowski, K., Rutkowska, K., Sierakowski, M., Nowinowski-Kruszelnicki, E., Dąbrowski, R. and Mergo, P., "Photonic Liquid Crystal Fibers with Polymers," Acta Phys. Pol. A 124(3), 613-616 (2013).

[11] Gao, Y., Guo, N., Gauvreau, B., Rajabian, M., Skorobogata, O., Pone, E., Zabeida, O., Martinu, L., Dubois, C. and Skorobogatiy, M., "Consecutive Solvent Evaporation and Co-Rolling Techniques for Polymer Multilayer Hollow Fiber Preform Fabrication,” J. Mater. Res. 21(9), 2246-2254 (2006).

[12] Gibson, G. T. T., Wright, R. D. and Oleschuk, R. D., "Multiple electrosprays generated from a single polycarbonate microstructured fibre," J. Mass Spectrom. 47(3), 271-276 (2012).

[13] Harrington, J., George, R., Pedersen, P. and Mueller, E., "Hollow polycarbonate waveguides with inner $\mathrm{Cu}$ coatings for delivery of terahertz radiation," Opt. Express 12(21), 5263-5268 (2004).

[14]Ziemman, O., Krauser, J., Zamzow, P. E. and Daum, W., [POF Handbook. Optical Short Range Transmission Systems], 2nd Edition, Springer, 37-231 (2008).

[15] Tanaka, A., Sawada, H., Takoshima, T. and Wakatsuki, N., "New plastic optical fiber using polycarbonate core and fluorescence-doped fiber for high temperature use," Fiber Integr. Opt. 7(2), 139-158 (1988).

[16] Yamashita, T. and Kamada, K., "Intrinsic Transmission Loss of Polycarbonate Core Optical Fiber," Jpn. J. Appl. Phys. 32(1), 2681-2686 (1993).

[17] Irie, S. and Nishiguchi, M., "Development of the heat resistant plastic optical fiber," Proc. of the Third International Conference on Plastic Optical Fibres \& Applications, pp. 88-91 (1994).

[18] Koike, Y., Ishigure, T. and Nihei, E., "High-Bandwidth Graded-Index Polymer Optical Fiber," J. Lightwave Technol. 13(7), 1475-1489 (1995).

[19] Fasano, A., Woyessa, G., Stajanca, P., Markos, C., Stefani, A., Nielsen, K., Rasmussen, H. K., Krebber, K. and Bang, O., "Fabrication and characterization of polycarbonate microstructured polymer optical fibers for hightemperature-resistant fiber Bragg grating strain sensors," Opt. Mater. Express 6(2), 649-659 (2016).

[20] Bundalo, I.-L., Nielsen, K., Markos, C. and Bang, O., "Bragg grating writing in PMMA microstructured polymer optical fibers in less than 7 minutes," Opt. Express 22(5), 5270-5276 (2014).

[21] Johnson, I. P., Kalli, K. and Webb, D. J., " $827 \mathrm{~nm}$ Bragg grating sensor in multimode microstructured polymer optical fibre," Electron. Lett. 46(17), 1217-1218 (2010).

[22] Stefani, A., Yuan, W., Markos, C. and Bang, O., "Narrow Bandwidth 850-nm Fiber Bragg Gratings in FewMode Polymer Optical Fibers," IEEE Photon. Technol. Lett. 23(10), 660-662 (2011).

[23] Yuan, W., Khan, L., Webb, D. J., Kalli, K., Rasmussen, H. K., Stefani, A. and Bang, O., "Humidity insensitive TOPAS polymer fiber Bragg grating sensor," Opt. Express 19(20), 19731-19739 (2011).

[24] Zhang, W. and Webb, D. J., "Humidity responsivity of poly(methyl methacrylate)-based optical fiber Bragg grating sensors," Opt. Lett. 39(10), 3026-3029 (2014). 